\title{
Message from the President
}

\section{"DEEP-DYED HEALTH IS THE ENTIRE HEALTH OF THE CHILD FROM TOTS TO TEENS, BIRTH TO ADULTHOOD.”}

Dear Colleagues,

A warm welcome to you all! I would like to begin by stating how honoured I am to be serving as your President for SAAPD. I feel extremely blessed to be a part of our special profession and this distinguished alliance. I love being a paediatric dentist and I truly believe I am doing what God has designed and planned for me to do. I am excited to have this opportunity to serve my colleagues in this capacity and am tremendously optimistic for the future of the SAAPD!

The South Asian Association of Paediatric Dentistry (SAAPD) exists to support that drive that lives in each of us to be the "best of the best". It is a platform for experts to congregate for effective exchange of ideas and skills relying on the belief that every child has a fundamental right to his total oral health. It is a consortium of dental professionals catering to a variety of populations with the goal of building healthy communities of children and with a vision that oral health is the key to general health and quality of life.

As we all look ahead to this coming year, when we implement the new Milestone of SAAPD in 2017 with the purpose to expand awareness, eliminate stigma and provide support for the programs served by Integral Care formerly known as SAAPD. We will focus on creating and promoting educational initiatives to our longstanding commitment to knowledge transfer through SAAPD'S Ist biennial conference going to be held in New Delhi from $4^{\text {th }}$ to $6^{\text {th }}$ May, 2018. We have created a committee who has been tasked with producing and vetting a curriculum that focuses on professional learning and education to the benefit of our members and the paediatric community at large.

Our time together is so valuable, and so limited, that we want to make it as useful to the association as possible. The website has been set-up in such a manner that it should be a way to readily communicate with the paediatric coterie, to facilitate the sharing of news \& resources and promote activities. In the first year of our founding, we continue to be inspired by the passion and commitment we see in the paediatric society. As we move forward, ensuring it continues to be a scientifically strong, transparent and relevant society. We will therefore try to orchestrate our sphere as much as possible (practically and legally, by our by-laws) electronically before we meet.

The past year, we went through a deliberate strategic forethought process. As a result, the mission of this organization has been defined and focused.

"The South Asian Association of Paediatric Dentistry (SAAPD) is a non-profit organization of individuals primarily concerned with area(s) of practice, education and research related to the field of Paediatric Dentistry. It provides a platform for the Paediatric Dentists of South Asia to work together in spirit of friendship, trust and understanding for benefit of the child's oral health."

By contributing exceptional educational experiences to our members and optimal health care to children, which include the latest and most relevant topics within our specialty, we hope to continue to offer unique opportunities to our Paediatric Society. These opportunities not only provide education, but also provide collegial environments where ideas on the practice of paediatric dentistry can be exchanged openly with your peers from across the country. I encourage every member to take advantage of these opportunities! Your collective support makes it possible for us to make a difference.

As President, I am particularly interested in hearing from you- How can we continue to inspire your lifelong commitment to excellence within our profession and federation?

Each comrade of conglomerate is working very hard to improve and increase the value of our membership and association. Each of our founder working members is listed on our website for your convenience. We are an approachable, fun, and hardworking group that would be happy to address any questions or ideas you may have. Without the significant contributions of these individuals, our fraternity would not be a strong syndicate that it is as today. I would like to extend the deepest gratitude to each one of them.

Become a part of our expanding family in case you have not yet registered as a member Our mission is clear and we are motivated! Please know that "The SAAPD" is here to help support your lifelong commitment to excellence and total oral health care for children'. 
I am sure you will keep our spirits high with words of encouragement and needed support for the growth of association. I also optimistic that we, together, will not be short of generating creative ideas in expanding the programs that directly benefit the association in future. With all your whack and liaison, SAAPD, I am sure, will grow and grow.

SAAPD is your association too. So, please feel free to guide and suggest us ways on how we can always better the lives of children we tirelessly serve. We will also keep you posted with the news and updates from our end.

Great words to live by! As individuals traveling the road of life, it is a difficult journey. Some live up to these words, but for most, life centres on our daily routine, moving from task to task without giving this path a second thought. For some, this is a way of life. But for me, this was second nature ...

I never ceased to fight for that and never let us lose sight of that goal. My message to the young and newer paediatric dentists is to become active within the SAAPD, to share their thoughts, ideas, passions and opinions. Just engage, I would say, at any level possible, so we, as paediatric dentists may continue to do what's essential to keep our specialty strong. You are among a committed group of colleagues who have the same high standard of excellence and professionalism.

The Journal of SAAPD is an attempt to publish relvant research, opinions, cases and reviews particular relevant to the region. I hope that this scientific face of the society help all of us in knowing more and sharng more. Our Editorial team has put hard work to compile the inauguration issue with a beautiful cover page. I am thankful to the Editorial team for putting efforts to bring the journal on the day of inauguration.

Again, thank you so much for this opportunity to serve as your President. I am looking forward to a great year! Thank you for joining us on our journey and express a hope that we will find mutual inspiration in the development of our Alliance. 